\title{
CROUZON'S DISEASE AND PITUITARY DYSFUNCTION* CROUZON'S DISEASE, HYPOPITUITARISM, ECTOPIA LENTIS, SECONDARY GLAUCOMA, AND IRIS ATROPHY IN A DEAF-MUTE FAMILY
}

BY

\author{
K. NATH, S. D. VIJAY, H. V. NEMA, AND B. R. SHUKLA
}

From the M.U. Institute of Ophthalmology and Gandhi Eye Hospital, Aligarh, India

SiNCE its first description by Crouzon in 1912, about a hundred cases of faciomandibular dysostosis have been added to the literature. Certain unusual features of the case described below throw light on the embryogenesis and evolution of this condition.

\section{Case Report}

A boy aged 14 from Nagina with features of Crouzon's disease was admitted to the Gandhi Eye Hospital on March 4, 1963 (Figs 1, 2, and 3), complaining of pain and gradual diminution of vision in both eyes.

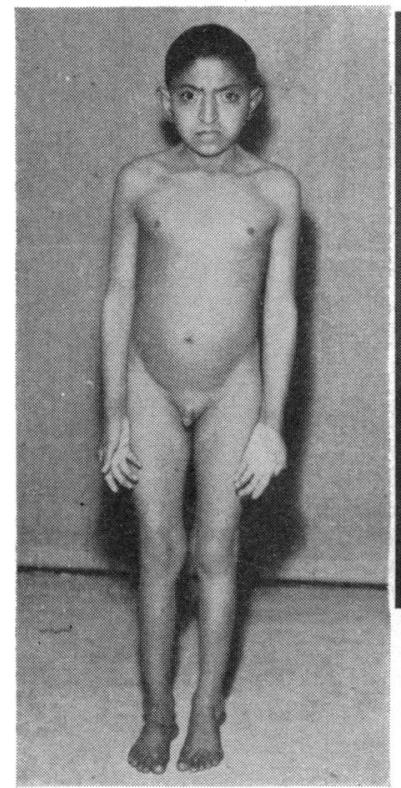

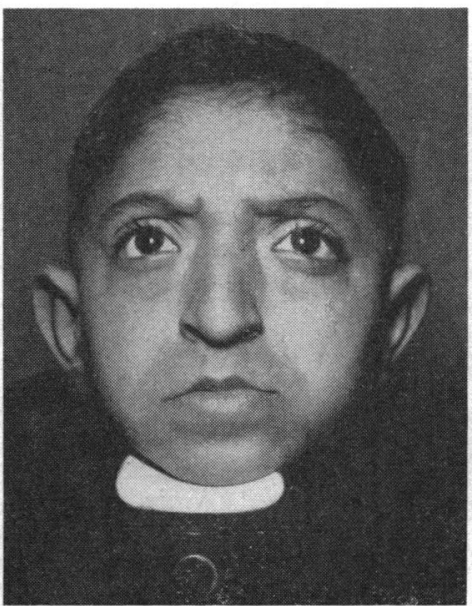

FIG. 2.-Anti-mongoloid obliquity, proptosis, divergent squint, parrot-nose, and prognathous lower jaw.

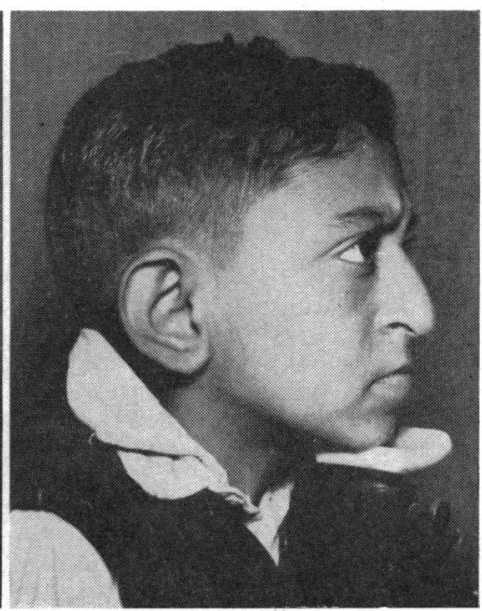

FIG. 3.-Same as Fig. 2 in profile.

FiG. 1.-A case of Crouzon's disease with hypopituitarism, dwarfism, hypogenitalism, and absence of pubic hair in a boy of 14 .

Since the age of 5 he had had occasional attacks of headache which lasted for an hour or so; these attacks continued until the age of 7 and then gradually waned. He had developed very slowly and did not sit up, eat, or talk until the age of 4 years, when his first teeth also appeared. He started standing and walking at the age of 6 years.

Examination.-He was a thin, underdeveloped, mentally deficient dwarf (Fig. 1), slightly deaf and with a nasal accent. He had frontal bossing (Fig. 3), parrot-nose (Figs 2 and 3), proptosis, divergent squint, shallow orbits, and a prognathous lower jaw (Figs 2, 3, and 4), the lower teeth being slightly in front of the upper teeth and the maxillae underdeveloped (Fig. 4, opposite). 
The circumference of the skull was $475 \mathrm{~mm}$., and the antero-posterior and transverse diameters 175 and $150 \mathrm{~mm}$.; the vertical and horizontal diameters of the orbits were 30 and $40 \mathrm{~mm}$. The patient was $122.5 \mathrm{~cm}$. tall. The chest was flat, unexpanded circumference $63 \mathrm{~cm}$. increased by only $2.5 \mathrm{~cm}$. on expansion. He weighed $65 \mathrm{lb}$.

He had the appearance of a boy aged 7 or 8 years, with no signs of secondary sexual characters, no pubic or axillary hair, and underdeveloped genital organs (Fig. 1). The resting pulse rate was 108 per minute and the blood pressure was $104 / 62 \mathrm{~mm}$. $\mathrm{Hg}$.

Eye Examination.-He had anti-mongoloid obliquity of the palpebral fissures (Fig. 2). The palpebral apertures were $13 \times 9 \mathrm{~mm}$. in the primary position of gaze and asymmetrical. The right medial canthus was $3 \mathrm{~mm}$. above the right outer canthus and the left $2 \mathrm{~mm}$. above the left outer canthus. Both orbits were shallow and both eyes proptosed. The apex of the right cornea was $1.4 \mathrm{~cm}$. in front of the outer orbital margin and the left was $1 \cdot 3 \mathrm{~cm}$. The distance between the two medial canthi was $4.4 \mathrm{~cm}$. The vertical corneal diameters were $11 \mathrm{~mm}$. and the horizontal $10 \mathrm{~mm}$. The radii of curvature were $7.7 \mathrm{~mm}$. all round in both eyes. The interpupillary distance was $65 \mathrm{~mm}$. and the B.T. $110 \mathrm{~mm}$. There was a divergent squint of $15^{\circ}$ in the left eye. The visual acuity was $3 / 60$.

The anterior chambers in both eyes were extremely shallow, the irides bulging forwards as if they were being pushed out from behind. The left eye had anterior synechiae at 12 and 9 o'clock from the region of the colarette, and the pupil dilatation was poor. The left iris also showed ectropion of uveal pigment at 12 o'clock, and was atrophic, particularly in the lower inner sector, with radial strands due to early generalized atrophy. The right iris was also atrophic below but had fewer radial strands than the left. Both lenses were dislocated up and in, and their edges could be seen in the pupillary area (Fig. 5). These findings were confirmed by slit-lamp examination. The dislocation of the lenses caused irregular reflexes in the pupillary area and the fundus could not be visualized. The pupils reacted fairly well to light. Tension by applanation was $30 \mathrm{~mm}$. $\mathrm{Hg}$ in each eye and with a $7.5 \mathrm{~g}$. weight it was 28 and $33 \mathrm{~mm}$. $\mathrm{Hg}$ (Schiötz) in right and left eye respectively.
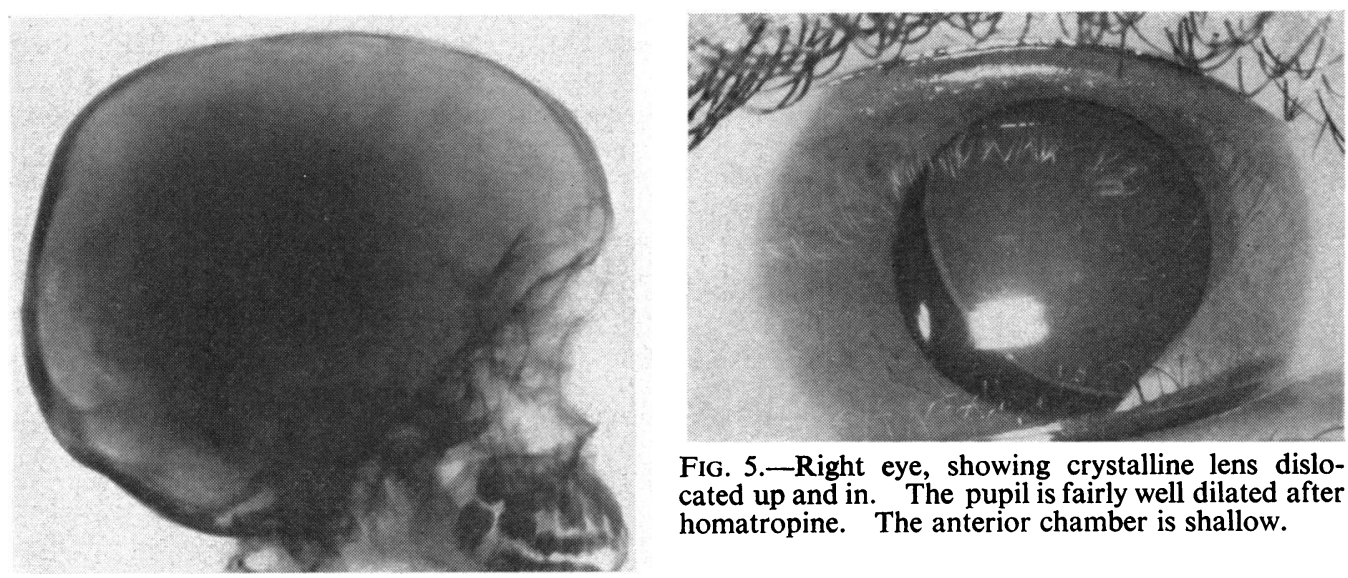

FIG. 5.-Right eye, showing crystalline lens dislocated up and in. The pupil is fairly well dilated after homatropine. The anterior chamber is shallow.

FIG. 4.-Lateral skiagram, showing irregularity of roof of skull. The coronal sutures are closed. The orbital roof is more oblique resulting in shallow orbits. The maxillae are underdeveloped. The lower incisors are seen in front of the upper ones.

Family History.-This boy, himself partly deaf, has one younger brother and a younger sister who are completely deaf and dumb. His mother is also deaf and dumb. The father is normal. The maternal grandfather, who was mentally deficient and subject to unreasonable bouts of laughing and crying, had two normal sisters a normal younger brother, and an elder brother who had attacks of acute insanity.

Investigations.-A lateral skiagram shows irregularity in the two tables of the roof of the skull, with closure of the coronal sutures. The orbital roofs are more vertical than usual and the orbits are shallow. The pituitary fossa is normal. The maxillae are very much underdeveloped, with a 
protruding lower jaw and the lower incisors a little anterior to the upper ones (Fig. 4). The optic foramina are enlarged and the outline of the left is ill-defined, particularly the roof (Fig. 6).

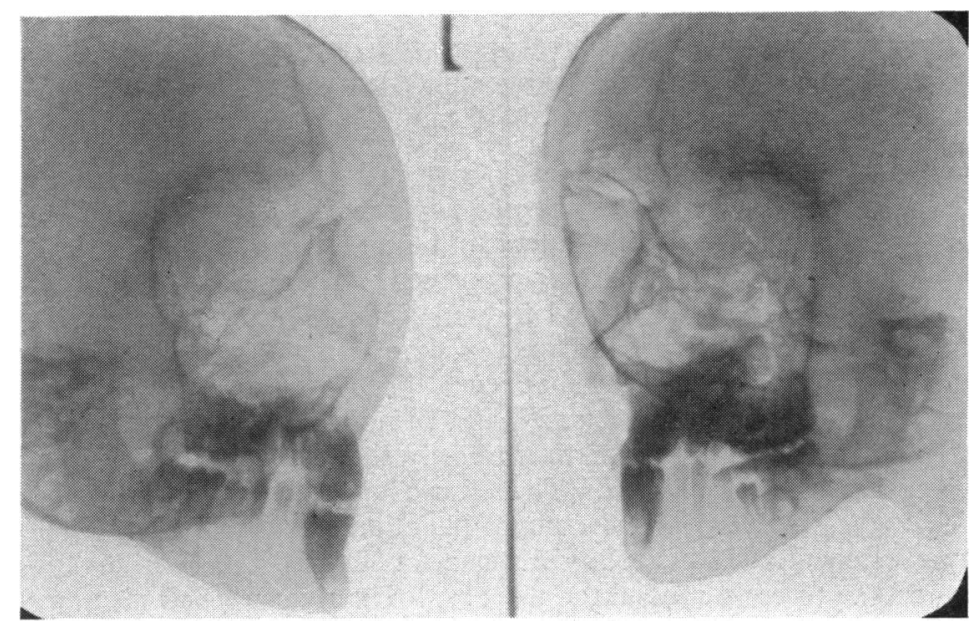

FIG. 6.-Skiagram, showing enlargement of optic foramina and deficient orbital roof on the left side.

Except for a flat sugar tolerance curve, the laboratory investigations for blood, C.S.F., urine, and stool were normal. The blood sugar did not rise beyond $100 \mathrm{mg}$. in 3 hours after $50 \mathrm{~g}$. glucose orally.

Treatment.-To counteract the rise in ocular tension the patient was kept on local 2 per cent. pilocarpine drops four times daily in each eye and oral Diamox, one tablet thrice daily. In a week the tension came down to $16 \mathrm{~mm}$. $\mathrm{Hg}$ (Schiötz) in each eye. The left lens was extracted on March 12,1963 , and the right on March 24, 1963. There was slight vitreous prolapse on both occasions. The lenses removed were scarcely half the size of adult lenses, showing that this patient had microphakia as well (Fig. 7).

FIG. 7.-Extracted lens (a) compared with a cataractous lens $(b)$ from a normal adult. (a)

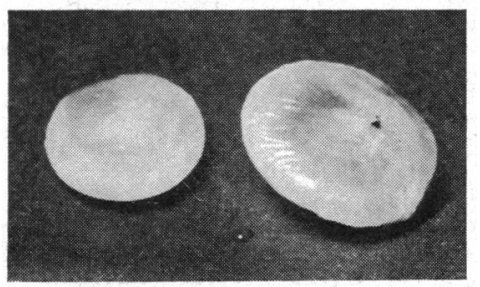

Result.-The visual acuity was $6 / 24$ in the right eye and 6/18 in the left with glasses. The fundus appearances were normal.

\section{Summary}

A case of Crouzon's disease was associated with hypopituitarism in a deaf-mute family. This is the second case of this disease in which ectopia lentis has been observed (cf. Caliglione and Bonoccorsi, 1960), and the first case of ectopia lentis with concomitant bilateral secondary glaucoma, iris atrophy, and microphakia. Unlike the usual cases, this patient had enlarged optic foramina with a deficient roof on the left side.

\section{REFERENCES}

Caliglione, G., and Bonoccorsi, A. (1960). Amer. J. Ophthal., 49, 200.

Crouzon, O. (1912). Bull. Soc. méd. Hôp. Paris, 3e sér., 33, 545. 